
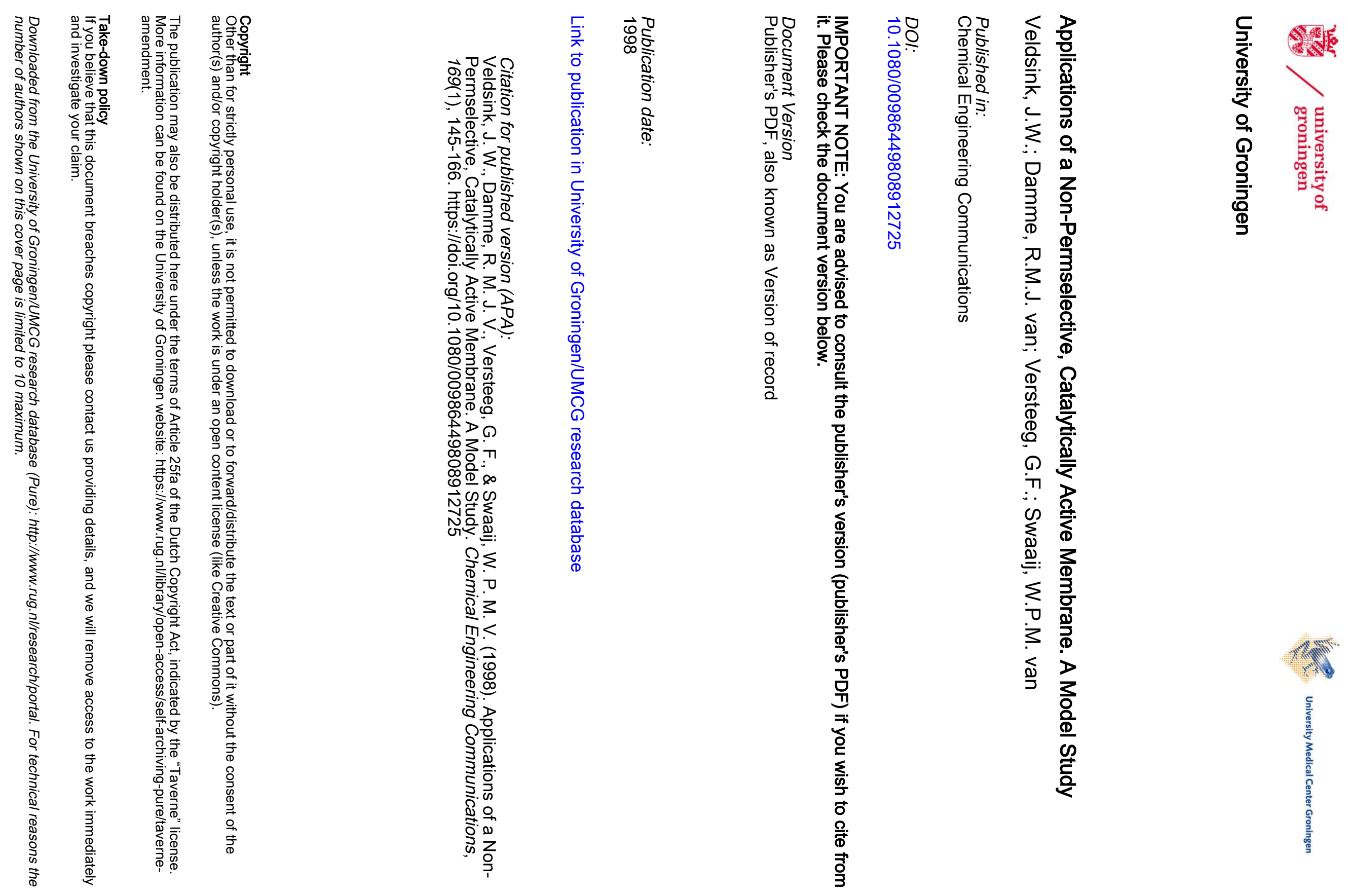


\title{
APPLICATIONS OF A NON-PERMSELECTIVE, CATALYTICALLY ACTIVE MEMBRANE. A MODEL STUDY
}

\author{
J. W. VELDSINK ${ }^{a}$ *, R. M. J. VAN DAMME ${ }^{b}$, G. F. VERSTEEG $^{a}$ \\ and W. P. M. VAN SWAAIJ ${ }^{a}$ \\ a Department of Chemical Engineering, University of Twente, \\ P.O. Box 217, NL-7500 AE, Enschede, The Netherlands; \\ ${ }^{\mathrm{b}}$ Department of applied Mathematics, University of Twente
}

(Received 5 August 1997; In final form 31 March 1998)

\begin{abstract}
A theoretical investigation has been presented for applications and features of a nonpermselective, catalytic membrane reactor with separated feed of reactors $[12-14,17,18]$. Transmembrane fluxes were calculated from the dusty gas model as a function of a great number of parameters and operation conditions. This study shows that the non-permselective, catalytic membrane reactor with separated feed of reactants (CMRSR) has attractive features to use this reactor in fast and highly exothermic reactions and selectivity improvement in multiple reactions.

When the CMRSR is operated in the transport controlled regime, the process is easy to control and even possesses some self-controllability. Due to the transport conversion, thermal runaway cannot occur which allows operation with concentrated feed of reactants. Furthermore, a transmembrane pressure difference increases both the fluxes and the selectivity, because the reaction products are preferentially directed towards one side of the membrane. The simultaneous increase of both selectivity and fluxes is a remarkable feature of a CMRSR which is in contrast with conventional reactors.
\end{abstract}

Keywords: Catalytic membrane reactor; dusty gas model; diffusion and reaction in membrane

\section{INTRODUCTION}

The use of membranes in chemical reactors has been widely studied, because the separation properties and catalytic activity can be combined into one

*Address for Correspondence: ATO-DLO, P.O. Box 17, NL-6700 AA Wageningen, The Netherlands. e-mail: j.w.veldsink@ato.dlo.nl 
device. Organic, polymeric, as well as inorganic, ceramic, membranes have been implemented, and a comprehensive overview of the present use of membrane reactors has recently been presented by [1]. Ceramic and metal membranes can be applied at elevated temperatures, are chemical resistant, and, additionally, can serve as catalyst support. As a consequence, ceramic nembranes appear more attractive to use in chemical reactors. Concise overviews of their application and properties of inorganic and metal membranes have been presented $[2,3]$.

Permselective membranes, dense or porous, are more permeable for particular components, and therefore, have been frequently studied in reactions suffering from thermodynamically limited conversions. Either the membrane is used as a permselective wall of a packed catalytic bed [4-7] or the membrane is catalytically active itself [8]. It has been demonstrated both experimentally $[8]$ and theroetically $[6,9]$ that membrane reactors allow conversion levels apparently beyond the thermodynamic equilibrium, due to selective intermediate product removal. However, in many cases the plug flow reactor with recycle might be preferred over the catalytic membrane reactor $[6,10]$. Furthermore, permselective membranes suffer from low transmembrane fluxes, which obstruct their application in industrial reactors.

Catalytic membrane reactors (CMR) have been demonstrated to exhibit several attractive features which are distinct from conventional reactors. Gryazov and coworkers [5] studied the concept of reactive coupling of endothermic and exothermic reactions for in-situ heat production. The intermediate product selectivity of consecutive reactions is substantially improved when a permselective membrane is introduced in a packed bed reactor [1I]. The concept of operation with feed of reactants separted by the membrane was studied for the Claus desulphurisation reactions $[12,13]$ and the catalytic $\mathrm{NO}_{x}$ reduction $[14, \mathrm{I}]$ ]. For the selective methanol conversion to formaldehyde in a catalytic membrane reactor (CMR), separation of the reactants resulted in higher selectivities than operating the membrane 'oncethrough', as a packed bed [I6]. Here, supply of reactants at opposite sides of the membrane added more flexibility and control to the reactors. Therefore, this type of CMR might offer a suitable alternative for reactions which are normally difficult to control, such as reactions which require a strict stoichiometric ratio of the reactant feed.

The CMR with separated feed of reactamts (CMRSR) as developed by [12-14] was experimentally demonstrated for non-equilibrium, catalytic oxidation reactions $[17-20]$. The CMRSR seems attractive for fast, highly exothermic reactions, because thermal runaway is avoided due to transport 
limited conversion in such a reactor [17-19]. The present study investigates attractive application areas for a non-permselective membrane reactor with separated feed of reactants (CMRSR). Therefore, transmembrane fluxes were calculated from the dusty gas model equations [21, 22] for a variety of operation conditions.

\section{THEORY}

In a porous medium, the local mass balance for a single component, $i$, reads:

$$
\frac{\varepsilon}{R_{g} T} \frac{\partial\left(x_{i} P\right)}{\partial t}=-\nabla N_{i}+R_{i}\left(x_{1}, \ldots, x_{n}, P, T\right) \quad\left(\mathrm{mol} \mathrm{m}_{\mathrm{cat}}^{-3} \mathrm{~s}^{-1}\right)
$$

Here, $R_{i}\left(x_{i}, \ldots, x_{n}, P, T\right)$ represents the local consumption or production rate according to a kinetic rate equation. The transport fluxes through the membrane, $N_{i}$, should, in general, be calculated from the dusty gas model $[21,22]$

$$
\sum_{j=1, j \neq i}^{n} \frac{x_{i} N_{j}-x_{j} N_{i}}{P D_{i j}^{e}}-\frac{N_{i}}{P D_{i, K}^{e}}=\frac{1}{R_{g} T} \frac{\partial x_{i}}{\partial z}+\frac{x_{i}}{P R_{g} T}\left(\frac{B_{0} P}{\mu D_{i, K}^{e}}+1\right) \frac{\partial P}{\partial z} \quad(i=1, \ldots, n)
$$

The diffusion coefficients are written as,

$$
\begin{gathered}
D_{i, K}^{e}=\frac{4}{3} K_{0} \sqrt{\frac{8 R_{g} T}{\pi M_{i}}}, \\
D_{i j}^{e}=\frac{\varepsilon}{\tau} D_{i j}^{0}
\end{gathered}
$$

The structure of the porous membrane is characterized by three parameters, $\varepsilon / \tau, K_{0}$ and $B_{0}$, which generally have to be determined experimentally. In case the pores are regarded as non-interconnected, circular capillaries of radius $r_{p}$, the values of $K_{0}$ and $B_{0}$ are directly calculated as a function of $r_{p}[21]:$

$$
\begin{aligned}
& K_{0}=\frac{\varepsilon r_{p}}{2 \tau} \\
& B_{0}=\frac{\varepsilon r_{p}^{2}}{8 \tau}
\end{aligned}
$$


The value of the porosity-tortuosity ratio, $\varepsilon / \tau$, can be derived from the results of $B_{0}$ and $K_{0}$ :

$$
\frac{\varepsilon}{\tau}=\frac{K_{0}^{2}}{2 B_{0}}
$$

The CMRSR is especially attractive for highly exothermic reactions, so the mass balances, in principle, must be coupled with the energy balance. The heat conductivity of porous alumina membranes, however, is comparatively high [23] so that temperature gradients in the membrane are not likely to occur at moderate partial pressures of the reactants. Furthermore, the analysis presented here will be restricted to the transport controlled regime (fast reactions) so fluxes are only weakly dependent on temperature. Therefore, in the present model, description of the mass transfer and reaction phenomena are assumed to proceed isothermal.

The equations were rewritten in a dimensionless form for the case of a general powerlaw kinetic rate expression, $R_{i}\left(x_{1}, \ldots, x_{n}, P, T\right)=\Sigma_{i} k_{r}(T)$ $\Pi_{j=1}^{n}\left(x_{j} P\right)^{m_{j}}$, and presented in Table I. Here, a dimensionless parameter $\alpha$ was introduced as the ratio between the Knudsen and bulk diffusion coefficients. Consequently, a membrane with $\alpha_{i}=0.1$ operates in the Knudsen regime, if $\alpha_{i}=1$ both Knudsen and bulk diffusion are important, and if $\alpha_{i}=10$ only bulk diffusion is important. Proper initial and boundary conditions are required to solve the set of equations, which are also presented in Table I. The external gas-to-membrane transport resistance was not taken into account for reasons of simplicity. The set of equations were numerically solved by a finite difference method.* An upwind differential scheme is necessary to maintain numerical stability at large convective flows.

\section{OPERATION CHARACTERISTICS OF A MEMBRANE REACTOR WITH SEPARATED FEED OF REACTANTS}

\subsection{Absence of a Pressure Difference Over the Membrane}

If pure $\mathrm{A}$ and $\mathrm{B}$ are present at equal pressures at opposite sides of a CMRSR, transport through the membrane of both A and B occurs as a result of the concentration gradients of both species. Furthermore, for a catalytically active membrane the transport is accompanied with a chemical reaction. The calculated mole fraction profiles of the reactants and products

- Details of the numerical treatment are available upon request from the first author. 
TABLE I Dimensionless model equations and parameters

parameters:

$$
\Pi=\frac{P}{P_{0}} \quad \zeta=\frac{z}{L} \quad \theta=\frac{D_{12}\left(P_{0}\right) t}{L^{2}} \quad \Phi_{i}=\frac{N_{i} L R_{g} T}{P_{0} D_{12}\left(P_{0}\right)}
$$

equations:

$$
\begin{gathered}
\varepsilon \frac{\partial\left(x_{i} \Pi\right)}{\partial \theta}=-\frac{\partial \Phi_{i}}{\partial \zeta}+\Sigma \Psi_{i, 0}^{2}(T) \prod_{j=1}^{n}\left(x_{j} \Pi\right)^{m_{j}} \\
\sum_{j=1, j \neq i}^{n} \frac{x_{i} \Phi_{j}-x_{j} \Phi_{i}}{\varepsilon / \tau \delta_{i j}^{\prime}}-\frac{\Phi_{i}}{\Pi \varepsilon / \tau \alpha_{i}}=\frac{\partial x_{i}}{\partial \zeta}+\frac{x_{i}}{\Pi}\left(\beta_{i} \Pi+1\right) \frac{\partial \Pi}{\partial \zeta} \quad(i=1, \ldots, n)
\end{gathered}
$$

constants:

$$
\begin{gathered}
\Psi_{0}^{2}=\frac{L^{2} k_{r}(T) R_{g} T P_{0}^{\left(-1+\Sigma_{j} m_{j}\right)}}{D_{12}\left(P_{0}\right)} \\
\delta_{i j}^{\prime}=\frac{\prod D_{i j}}{D_{12}\left(P_{0}\right)} \quad \alpha_{i}=\frac{D_{i, K}^{e}}{\varepsilon / \tau D_{12}\left(P_{0}\right)}, \quad \beta_{i}=\frac{P_{0} B_{0}}{\mu D_{i, K}^{e}}
\end{gathered}
$$

boundary conditions:

$$
\begin{array}{rll}
\theta=0: \Pi(0, \zeta)=\Pi(\zeta), & \forall \zeta, \quad i=1, \ldots, n \\
\zeta=0: \Pi(\theta, 0)=\Pi(0), & \forall \theta, \quad i=1, \ldots, n \\
\zeta=1: \Pi(\theta, 1)=\Pi(1), & \forall \theta, \quad i=1, \ldots, n
\end{array}
$$

are shown in Figure 2 for a reaction $\mathrm{A}+\mathrm{B} \rightarrow 2 \mathrm{C}$ and $R_{A}=-k_{1,1}(T) p_{A} p_{B}$. There is no net change in the number of molecules occurs and no pressure gradient occurs over the membrane.

For small $\Psi_{0}^{2}=L^{2} k_{1,1}(T) R_{g} T P_{0} / D_{A B}\left(P_{0}\right)$, see Table $\mathrm{I}$, the reaction rate is insufficiently fäst to convert the influx of reactants inside the membrane completely, and slip of unconverted reactants occurs as a result. For high $\Psi_{0}^{2}$, fast reaction, the reactants are completely converted inside the membrane and slip of reactants is absent as can be seen from Figure 2. Under these conditions a reaction zone can be distinguished which contracts at increasing $\Psi_{0}^{2}$ until finally a reaction plane appears. Figure 3 plots the corresponding fluxes of $A$ as a function of $\Psi_{0}^{2}$. The fast and instantaneous regimes, $\Psi_{0}^{2} \gg 1$ are easily achieved, for instance, for combustion of hydrocarbons at atmospheric pressures: $\Psi_{0}^{2} \geq 10$ for methane oxidation over $\mathrm{CuO}$ at $T \geq 810 \mathrm{~K}$ [24] or when $\mathrm{Pt}$ is the catalyst in this reaction $\Psi_{0}^{2} \geq 10^{3}$ for $T \geq 700 \mathrm{~K}[25]$. 


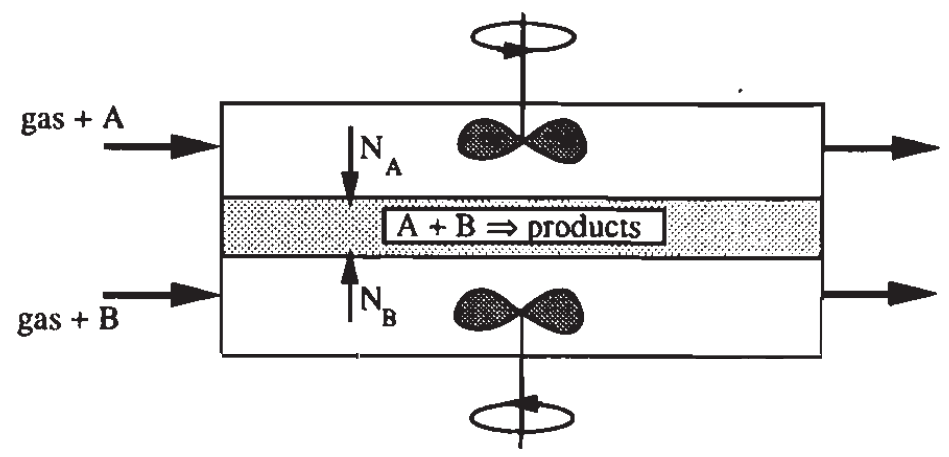

fibGURE ${ }_{1}$ l Concept of a membrane reactor with separated feed of reactants. The reactants $A$ and $B$ diffuse into the membrane from opposite sides, while the products of the reaction diffuse to both gas volumes.
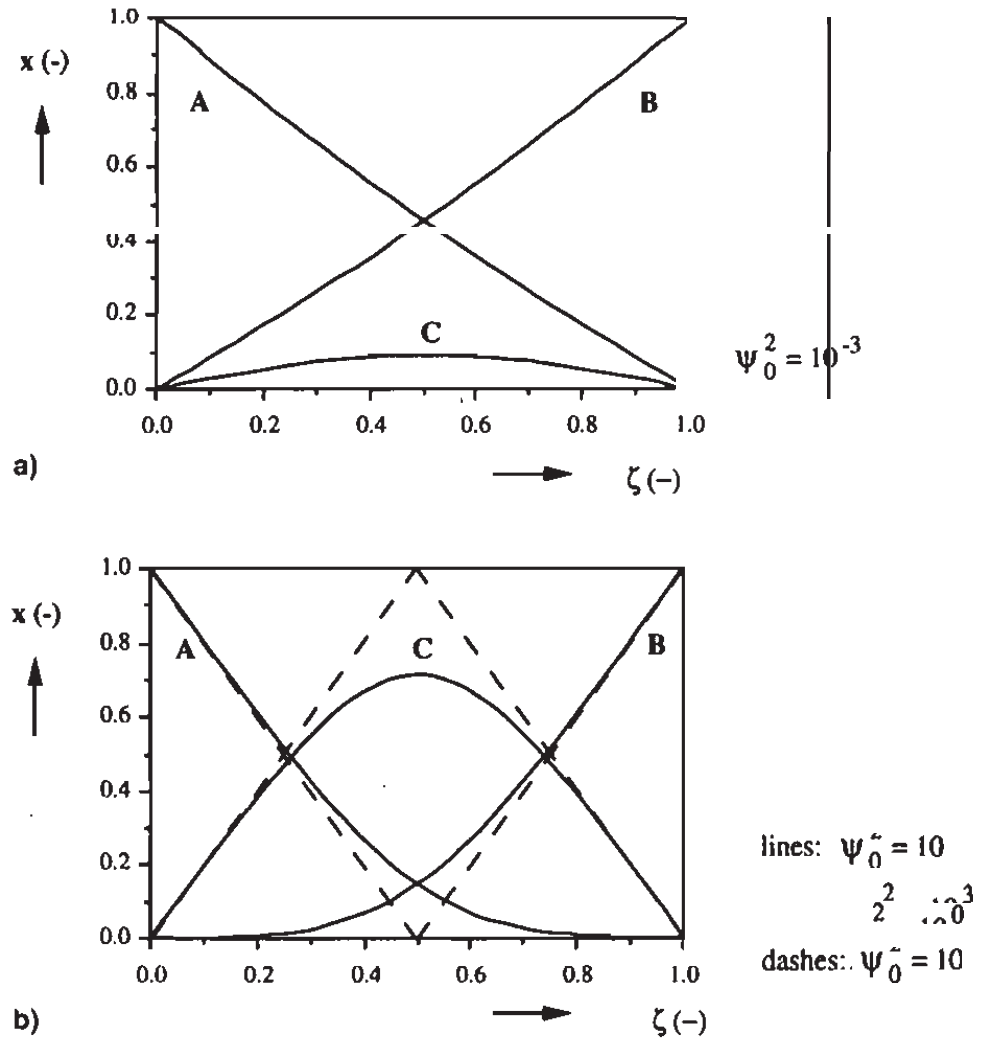

FIGURE 2 Mole fraction profiles of the reactants and products over the membrane for a reaction $\mathrm{A}+\mathrm{B} \rightarrow 2 \mathrm{C}$ with $(1,1)$-order kinetics and in the absence of a pressure difference over the membrane. Model parameters: $\delta_{i j}^{\prime}=1 ; \alpha_{i}=1 ; \beta_{i}=1$; a: slow reaction, $\Psi_{0}^{2}=10^{-3}$. b: fast reaction, $\Psi_{0}^{2}=1$, (full lines) and instantaneous reaction, $\Psi_{0}^{2}=10^{3}$ (dashed lines). 


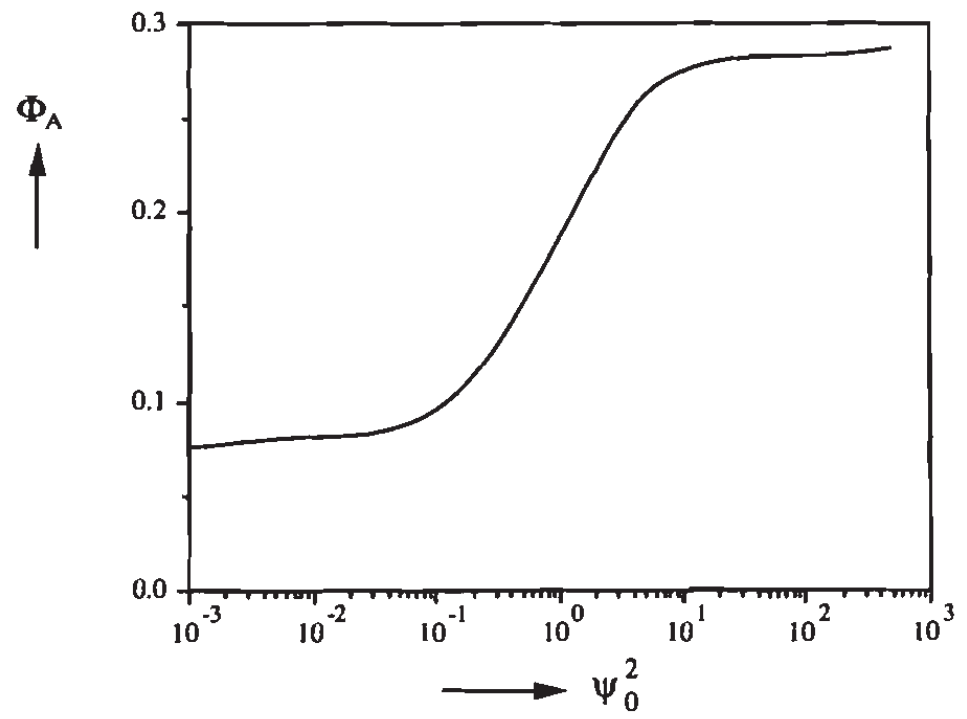

FIGURE 3 Transmembrane fluxes of reactant $A$ as a function of the modified Thiele modulus, $\Psi_{0}^{2}$, for the reaction $\mathrm{A}+\mathrm{B} \rightarrow 2 \mathrm{C}$.

The concentration profiles over the membrane in the case of separated feed of reactants closely resemble gas absorption in a reactive liquid with diffusion limitation of both reactants [26]. The flux of A gradually increases as a function of $\Psi_{0}^{2}$ and attains a maximum value, see Figure 3, similar to the maximum enhancement in $\mathrm{G}-\mathrm{L}$ systems. It has already been shown $[12,17$, 18] that at isobaric conditions the flux can be obtained from:

$$
N_{A}=N_{A, \text { physical }} E_{A, \infty}=N_{A, \text { physical }}\left(1+\frac{D_{B, \text { eff }} c_{B}^{1}}{\nu_{B} D_{A, \text { eff }} c_{A}^{0}}\right)
$$

Generally, however, the maximum enhancement factor, $E_{A, \infty}$, depends on both the pressure gradient and the transport regime, $\alpha$.

The dependence of the $E_{A, \infty}$ on the pressure gradient and transport regime is demonstrated for the general reaction scheme,

$$
\mathrm{A}+\mathrm{B} \rightarrow m C \text { with } \quad R_{A}=-k_{1,1} p_{A} p_{B}
$$

Figure 4 shows the concentration profiles over the membrane for the case $m=1$. A pressure gradient is present due to the volume change caused by the reaction. The effect of such reaction-induced pressure gradients on the maximum enhancement factor is demonstrated in Figure 5 which gives the 


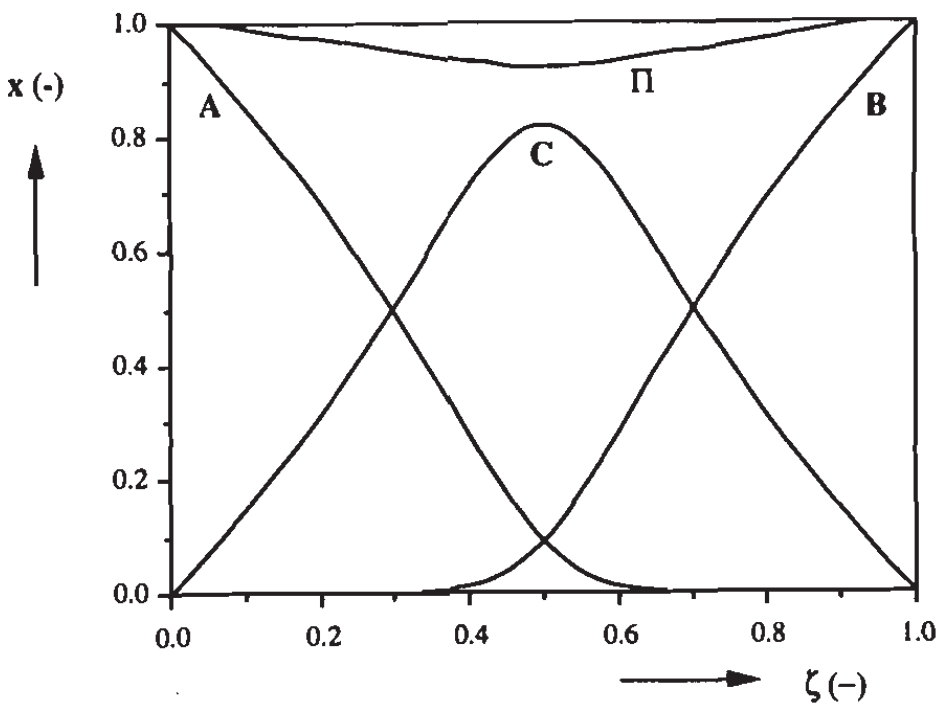

FIGURE 4 Dimensionless profiles of the reactants (A, B), products (C), and pressure over the membrane for a reaction $A+B \rightarrow 2 C$ with $(1,1)$-order kinectics and $\Psi_{0}^{2}=2$. An overall pressure difference over the membrane was absent.

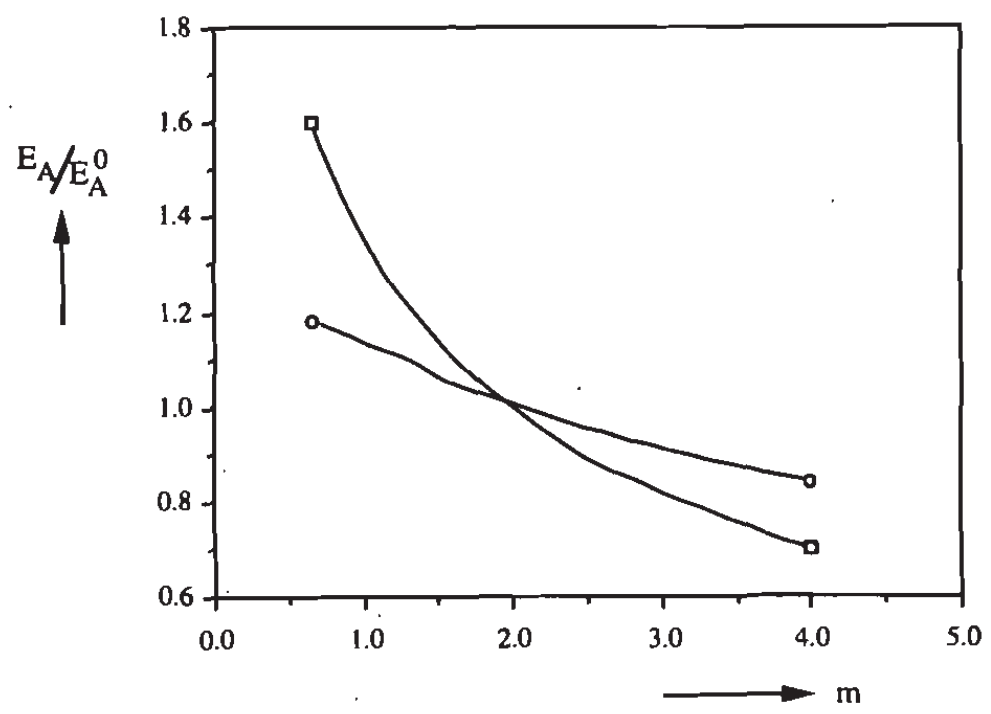

FIGURE 5 The enhancement factor, Eq. (8), for a reaction $\mathrm{A}+\mathrm{B} \rightarrow m \mathrm{C}$ divided by the enhancement factor for $m=2$ (no volume change) plotted as a function of the stoichiometric coefficient, $m$. The results are shown for a membrane with $\alpha=1$ (口) and $\alpha=0.1(0) . \Psi_{0}^{2}=20$. 
ratio of the enhancement factor calculated from the numerical fluxes and the enhancement factor calculated from Eq. (8) for various values of $m$ of the above-mentioned reaction scheme. From Figure 5 it can be conlcuded that Eq. (8) is restricted to pure isobaric systems. Unfortunately no simple expressions for the enhancement factor, such as Eq. (8), can be given which take into account the effects of pressure gradient and the transport regime.

If the membrane is sufficiently active, the fluxes are completely determined by the transport rates, see Figure 2, and the CMRSR exploits limited selfcontrollability. Under steady-state conditions the reaction plane (or zone) will be located so that the transprot rates of the reactants, A and B, comply to the reaction stoichiometry. If for instance the concentration of $A$ increases, as a consequence its flux will increase, and excess $\mathrm{A}$ will be present at the reaction plane. This excess of $\mathrm{A}$ diffuses further into the membrane and reacts with $B$. Consequently, the location of the reaction plane shifts towards the B-side of the membrane. This results in an increased diffusion path and, hence, a decreased flux of $\mathrm{A}$, and vice versa for component $\mathrm{B}$. This process will continue until finally the fluxes of $A$ and $B$ are in stoichiometric ratio again. This phenomenon of (limited) self-controllability of the CMRSR seems a very promising alternative for the processing of heterogeneous reactions requiring strict stoichiometric feed ratio of reactants, such as the $\mathrm{NO}_{x}$-reduction with ammonia $[14,15]$ or Claus desulphurisation reaction $[12,13]$.

\subsection{Transport in the Presence of a Transmembrane Pressure Difference}

This section discusses the influence of a transmembrane pressure difference on the transport rates of the reactants and products. Typical concentration profiles are shown in Figure 6 for a general reaction $\mathrm{A}+\mathrm{B} \rightarrow 2 \mathrm{C}$ with second-order overall kinectics, $R_{A}=-k_{1,1} p_{A} p_{B}$. It can be observed that the application of a pressure difference results in both a shift of the reaction zone to the low pressure side of the membrane and an expansion of the reaction zone as a result of increased fluxes at constant kinetic rate. The increase in the reaction zone can be attributed to the increase of the transport rate, whereas the activity of the membrane remains constant.

The corresponding flux of reactant $B$ as a function of the transmembrane pressure difference is shown in Figure 7. Reactant B is present at the high pressure side of the membrane, so its transport is aided by the convective flow. According to Eq. (2) the transport of B increases proportionally with the pressure difference in case the convective flow determines the total transport rate. Further, Figure 7 also presents the total rate of product 


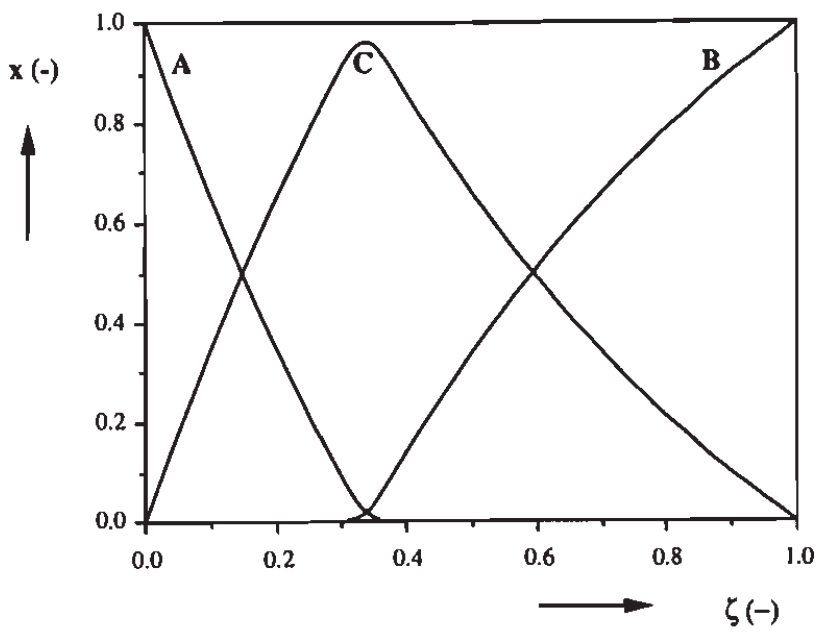

$\Delta \Pi=0.2$

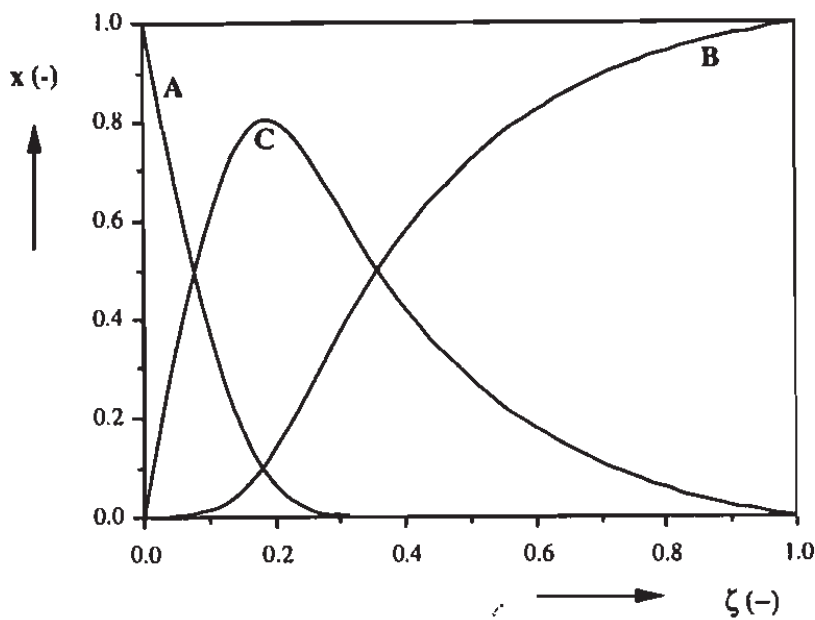

$\Delta \mathrm{\Gamma} \mathrm{l}=0.5$

FIGURE 6 Dimensionless profiles over the membrane at different pressure differences over the membranc are shown for a reaction $A+B \rightarrow 2 C$. Component $B$ is present at the high pressure side. Model parameters: $\Psi_{0}^{2}=10^{3} ; \alpha_{i}=1 ; \beta_{i}=1 ; \delta_{i j}^{\prime}=1$.

formation normalized to the flux of $\mathrm{B}$, defined as the sum of the absolute fluxes of $\mathrm{C}$ to both sides divided by its stoichiometric coefficient, as a function of the pressure difference. From Figure 7 it follows that the product flux attains a maximum as a function of the pressure difference.

The occurrence of a maximum product flux is explained from the transport rate of reactant $\mathrm{A}$. Additional viscous drag decreases transport of $\mathrm{A}$, 


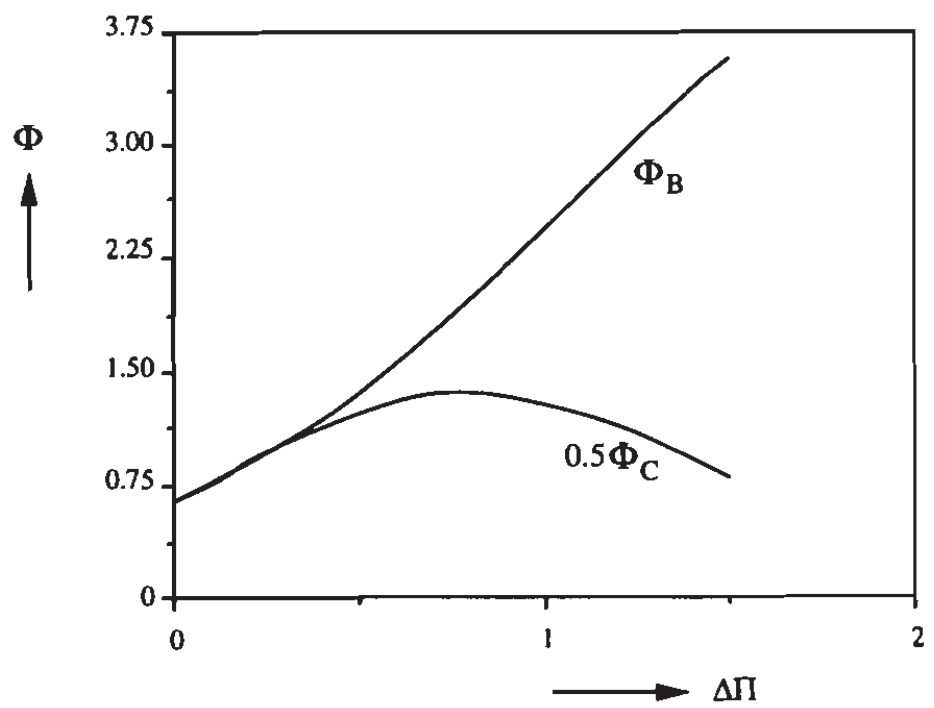

FIGURE 7 Dimensionless fluxes of $\mathrm{A}$ and $\mathrm{C}$ as a function of the pressure difference for a reaction $\mathrm{A}+\mathrm{B} \rightarrow 2 \mathrm{C}$. Component $\mathrm{A}$ is present at the high pressure side, and $N_{\mathrm{C}}$ is defined as the sum of the absolute fluxes at both membrane interfaces (total production rate of $\mathrm{C}$ ). Parameters: $\Psi_{0}^{2}=20 ; \alpha_{i}=1 ; \beta_{i}=1 ; \delta_{i j}^{\prime}=1$.

whereas the shorter diffusion length, see Figure 6, increases the flux simultaneously. Apparently at small pressure differences the latter effect compensates the convective drag and, initially, the total production rate increases and, subsequently, attains a maximum value. Before attaining its maximum, however, the transport rate of $\mathrm{A}$ has become insufficient to convert the total flux of $\mathrm{B}$, however and slip of $\mathrm{B}$ occurs.

As a consequence of the shifting reaction zone towards the low pressure side of the membrane, the transport of the products towards this side is highly favoured, caused by both a shorter distance and the assistance by the convective flow. This effect is demonstrated in Figure 8 plotting the ratio of the high pressure side over the low pressure side flux of product $\mathrm{C}$, as a function of the pressure difference over the membrane. Results are presented for a membrane operating in the transition diffusion regime, $\alpha=1$, and in the Knudsen regime, $\alpha=0.1$, respectively. The effect of a transmembrane pressure difference decreases with the pore radius because in the Knudsen regime components move with their own molecular velocity, unaffected by motion of other components through the membrane.

From Figures $6-8$, it can be concluded that the application of a pressure difference over the membrane is a powerful operation parameter for a nonpermselective CMRSR. 


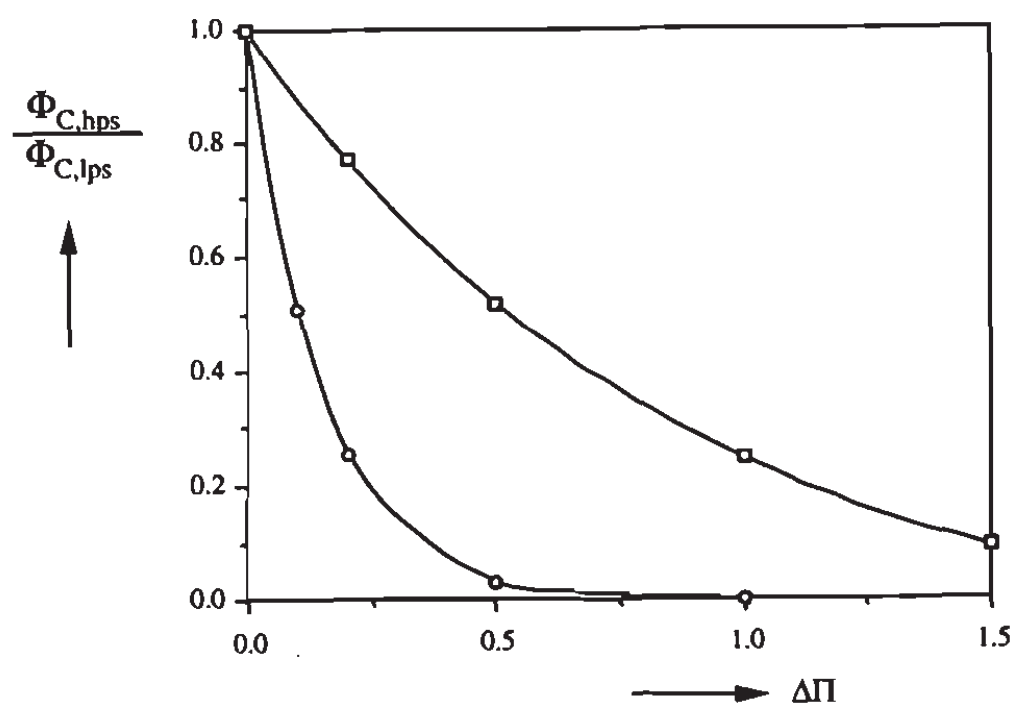

FIGURE 8 Ratio of product flux to the high pressure side over the flux to the low pressure side. Results are presented for diferent transport regimes, $\alpha=1$ (口) and $\alpha=0.1$ (०). Parameters: $\Psi_{0}^{2}=20 ; \beta_{i}=1 ; \delta_{i j}^{\prime}=1$.

\subsection{Application of a Catalytic Membrane Reactor with Separated Feed of Reactants}

\section{3.l. Equilibrium Reactions}

Extensive studies of overall conversion of equilibrium reactions carried out in a CMR with a permselective membrane have already been presented [6, 9]. Up till now, only permselective membrane, operating in the Knudsen regime, have been considered, because the differences in mobilities among the mixture components is most pronounced as the mobilities are proportional, to the square root of their molecular mass. Here we will extend this analysis also to non-permselective membranes operating in the transition regime between Knudsen and molecular diffusion.

Overall conversions were calculated for a CMRSR as in Figure 1 for a hydrogenation

$$
\mathrm{A}+m \mathrm{H}_{2} \leftrightarrow \mathrm{B} \quad R_{A}=-k_{h}\left(p_{A} p_{H_{2}}^{m}-p_{B} / K_{\mathrm{hyd}}\right)
$$

which typically invloves a volume decrease, $\Delta n<0$, as well as a dehydrogenation reaction,

$$
\mathrm{A} \leftrightarrow \mathrm{B}+m \mathrm{H}_{2} \quad R_{A}=-k_{d}\left(p_{A}-p_{B} p_{\mathrm{H}_{2}}^{m} / K_{\text {dehyd }}\right)
$$


which usually involves a volume increase, $\Delta n>0$. The thermodynamic equilibrium constant is defined as the ratio of the forward and backward rate constants $K_{\text {hyd, dehyd }}=k_{f} / k_{b}$. The physicochemical parameters are shown in Table II and the boundary conditions are given in Table I, but perfectly mixed gas phases were assumed to be present at both sides of the membrane [27]. It should be noted that the effects of co- and counter-current operation are not discussed, because the present CMR contains only one equilibrium stage.

In the absence of a transmembrane pressure differnce, Figure 9 plots the conversion that can be obtained in a CMRSR against the equilibrium conversion calculated at inlet conditions. Figure 9 shows that a CMRSR is only favoured when the reaction involves an increase in the number of molecules a CMR. These results are in full agreement with the work of [6] for permselective membranes. The maximum conversion is not affected by diffusion regime once the CMR operates close to local equilibrium and depends only of the type of reaction. Therefore, its higher fluxes favour the non-permselective membrane reactor over a permselective CMR. Generally, a plug flow reactor with product recycle operating at low partial pressures of $A$ is recommended for equilibrium reactions with a volume increase $[6,7$, $9,10]$. A non-permselective CMR, however, may provide an alternative when large product recycles are not desired due to downstream processing requirements.

\subsubsection{Intermediate Product Yield Enhancement}

The differences in mobilities among different species within a porous matrix has also been recognised as potentially useful to increase the yield towards intermediate products in consecutive reactions (see [7, 28]). It has been shown that the intermediate product yield is substantially increased at decreasing degree of utilisation of the active membrane layer [28]. Further, the feed conditions should be chosen such that the intermediate product formation is concentrated near the outer surface of the membrane, which is

TABLE II Physicochemical parameters

\begin{tabular}{lllll}
\hline Constant & $A$ & $B$ & Inert & $H_{2}$ \\
\hline$\alpha_{i}$ & 1 & 1 & 2 & 6 \\
$\beta_{i}^{\prime}$ & 0.4 & 0.4 & 0.7 & 4 \\
$\delta_{A, j}^{\prime}$ & - & 1 & 4 & 10 \\
$\delta_{B, j}^{\prime}$ & 1 & - & 4 & 10 \\
$\delta_{\text {incri,j }}^{\prime}$ & 4 & 4 & - & 10 \\
\hline
\end{tabular}




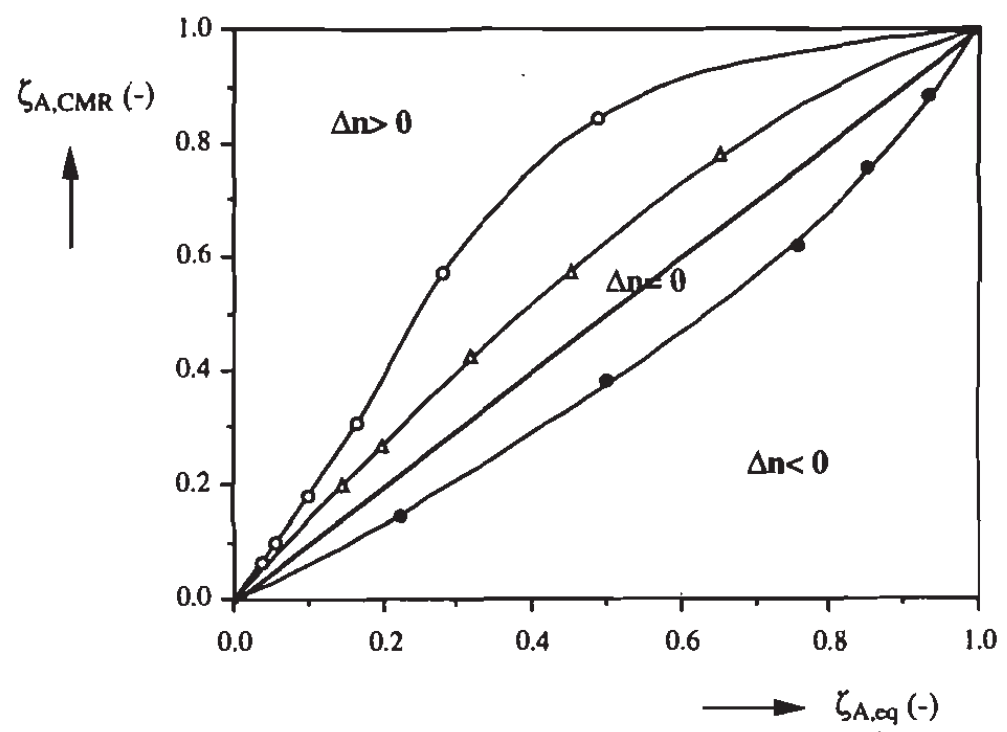

FIGURE 9 Plot of the conversion in a membrane reactor setup as depicted in Figure 1 as a function of the equilibrium conversion calculated for inlet concentrations. The results are shown for reactions involving an increasing $(\Delta n=3(0) ; \Delta n=1(\Delta))$, a decreasing number of molecules $(n=-3(\bullet))$, and no volume change.

easily achieved by separation of the reactants. This section presents calculations for a consecutive reaction system,

$$
\begin{gathered}
\mathrm{A}+0.5 \mathrm{O}_{2} \rightarrow \mathrm{B} \quad \mathrm{R}_{A}=-k_{1} p_{A} p_{\mathrm{O}_{2}} \\
\mathrm{~B}+4 \mathrm{O}_{2} \rightarrow 3 \mathrm{CO}_{2}+3 \mathrm{H}_{2} \mathrm{O} \quad \mathrm{R}_{B}=-k_{2} p_{B} p_{\mathrm{O}_{2}}
\end{gathered}
$$

which is a typical example of a partial oxidation scheme and often the product $\mathrm{B}$ is the desired product.

In general, the selectivity towards the intermediate product can be increased if contact between $\mathrm{B}$ and $\mathrm{O}_{2}$ can be avoided. Normally this is done by operating the reactor at low concentration levels of $\mathrm{B}$ which requires high recycles. In a membrane reactor, however, a (selective) transport resistance may prevent $\mathrm{B}$ from contact with $\mathrm{O}_{2}$ and, hence, increase the $\mathrm{B}$-yield. It was demonstrated in Section 3.2 that the application of a pressure difference over the membrane directs the reaction products preferentially towards one side of the membrane. This phenomenon can be used to prevent the desired reaction product from recombination with one of the reactants to undesired products and so result in an increased selectivity. 
This section discusses the opportunities to use a membrane reactor for intermediate product yield enhancement by application of either a permselective layer or a transmembrane pressure difference. Table III shows the transport parameters used in the calculations. The selectivity of the reaction scheme is defined as the flux ratio of $\mathrm{A}$ and $\mathrm{B}$ :

$$
\sigma_{B}=\frac{\left|N_{\mathrm{B}, \mathrm{A}-\text { side }}\right|+\left|N_{\mathrm{B}, \mathrm{B}-\text { side }}\right|}{\left|N_{\mathrm{A}, \mathrm{A}-\text { side }}-N_{\mathrm{A}, \mathrm{B}-\text { side }}\right|}
$$

3.3.2.1. Top-layer For the present system the selectivity improvement is studied as a function of the thickness of the inert diffusion barrier for operation in the transport controlled regime. In contrast with the work by Harold et al. [28], in the present setup the macroporous layer was active and the microporous top layer served only as a permselective transport barrier. In line with [28] for $(0,1)$-order kinetics, we also observed from our general model that the optimum selectivity was obtained at low degrees of utilisation of the active layer.

The calculated selectivities and fluxes are plotted as a function of the relative thickness of the top layer in Figures 10 and 11, respectively. Figure 10 shows that, theoretically, almost perfect selectivity can be achieved by a sufficient increase of the membrane thickness. However, increasing the selectivity simultaneously decreases the fluxes, see Figure 11. Consequently, such a CMRSR has similar characteristics to conventional continuous reactors operated at low concentration levels of the reactants.

A typical concentration profile over the asymmetric membrane is shown in Figure 12. It can be seen that, for a sufficiently, thick top-layer, the

TABLE III Model parameters for the calculations on the selectivity of a consecutive reaction given by Eq. (12) + (13)

\begin{tabular}{|c|c|c|c|c|c|}
\hline Constant & $1^{4}$ & $2^{a}$ & $3^{\prime \prime}$ & $4^{\mathrm{a}}$ & 5 * \\
\hline & 1 & 1 & 1 & 1 & 2 \\
\hline$\beta_{i}$ & 2 & 2 & 2 & 2 & 4 \\
\hline $\begin{array}{l}\delta_{1, i}^{\prime} \\
\delta_{2}^{\prime}\end{array}$ & $\overline{1}$ & - & & & \\
\hline $\begin{array}{l}o_{2, i} \\
\delta_{3, i, i}\end{array}$ & $1 / 3$ & $2 / 3$ & - & & \\
\hline$\delta_{4, i}^{*, i}$ & $2 / 3$ & 1 & $2 / 3$ & - & \\
\hline$\delta_{5, i}^{, i, t}$ & $5 / 3$ & $2 / 3$ & $5 / 3$ & $2 / 3$ & - \\
\hline \multicolumn{2}{|c|}{$\Psi_{1,0}^{2}=40$} & \multicolumn{2}{|c|}{$\Psi_{2,0}^{2}=10$} & & \\
\hline
\end{tabular}

$\mathrm{B} I=\mathrm{A} ; 2=\mathrm{O}_{2} ; 3=\mathrm{B} ; 4=\mathrm{CO}_{2} ; 5=\mathrm{H}_{2} \mathrm{O}$. 


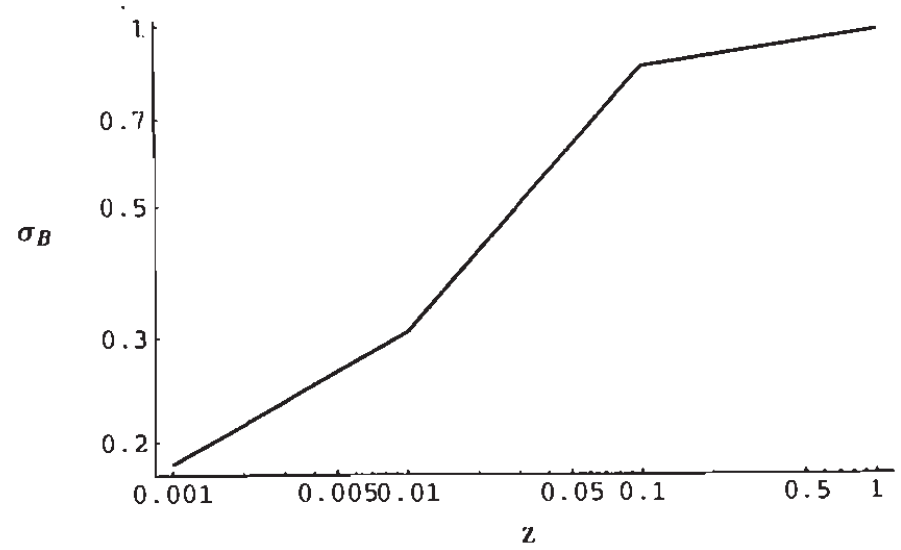

FIGURE 10 Selectivity towards B as a function of relative thickness of the inert micro-pore layer for a consecutive reaction, see Eq. (13).

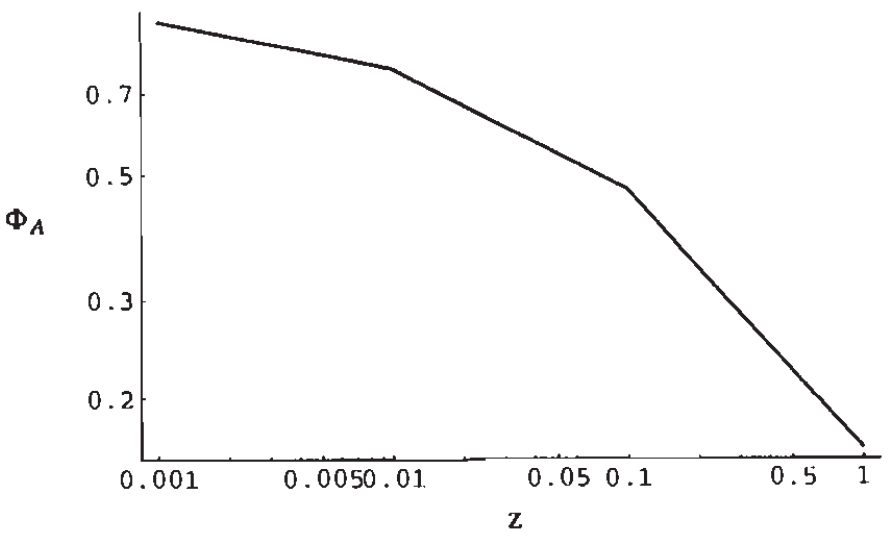

FIGURE 11 Total flux of A through the membrane as a function of realtive thickness of the inert top layer for a consecutive reaction, see Eq. (13).

depletion of oxygen occurs at the interface between the two layers. The product $B$ is formed at the interface and moves to both the oxygen side and the A-side of the membrane. Preferential transport to the A-side occurs due to the fact that the inert layer is permselective. The higher mobility of B in the non-permselective layer results in a preferential transport in the Adirection despite of the lower driving force. As a result of the oxygen depletion directly at the interface between the two layers, the selectivity towards B is expected to improve markedly. It also becomes apparent from the concentration profiles that slip of $\mathrm{A}$ to the oxygen side occurs. This is 


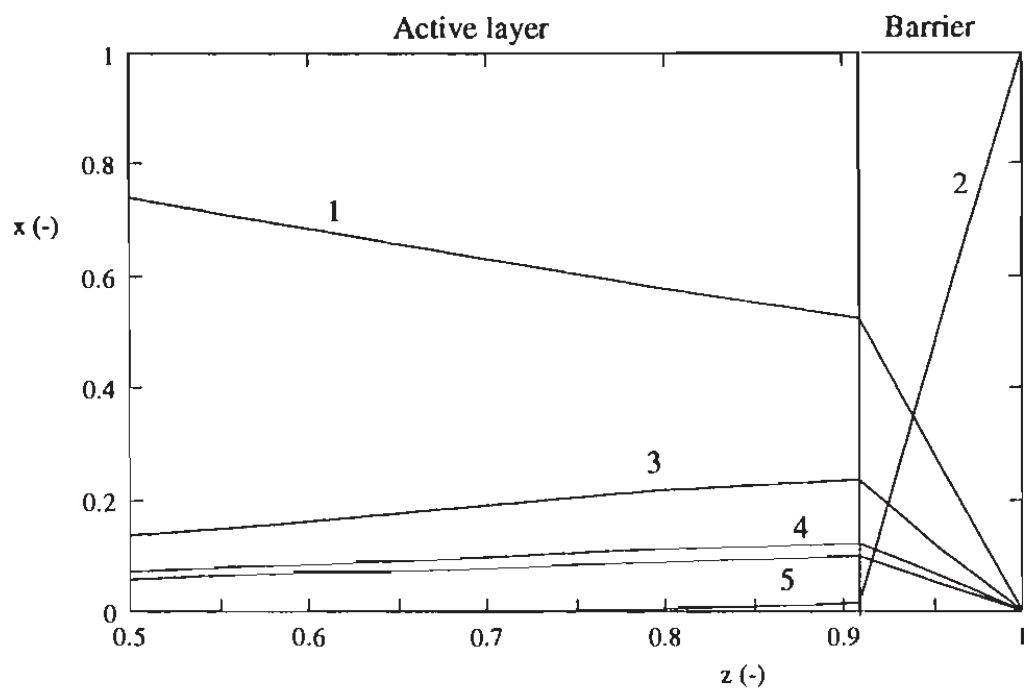

FIGURE 12 Typical profiles of reactants and products over the membrane for the reaction as given in Eq. (13). Here an inert top-layer of relative thickness $z_{\text {iner }} / z_{\text {active }}=0.1$ is present at the oxygen side. Index correspondence as in Table III.

not seriously affecting the operating characteristics, since the top-layer is inert.

\subsubsection{Pressure Difference As was mentioned before, preferential} transport of products in a membrane reactor is also possible by application of a transmembrane pressure difference. For the present reaction system the pressure gradient can be used to direct the transport of B toward the A-side, thus preventing the intermediate product to decompose with $\mathrm{O}_{2}$. The effect of a transmembrane pressure difference is demonstrated in Figure 13 which plots the concentration profiles over the membrane. Figure 13 demonstrates that the reaction zone is shifted towards the low pressure side of the membrane by the viscous flow, which is induced by the pressure difference. Transport of the intermediate product towards the low pressure side is favoured due to convective aided transport and a shorter diffusion path. As a consequence the selectivity may be expected to improve as a function of the transmembrane pressure difference.

The corresponding fluxes and selectivities are presented as a function of the pressure difference in Figures 14 and 15, respectively. The selectivity increases due to the preferential transport of intermediate product to the low pressure side. In contrast with the use of a permselective top layer, 


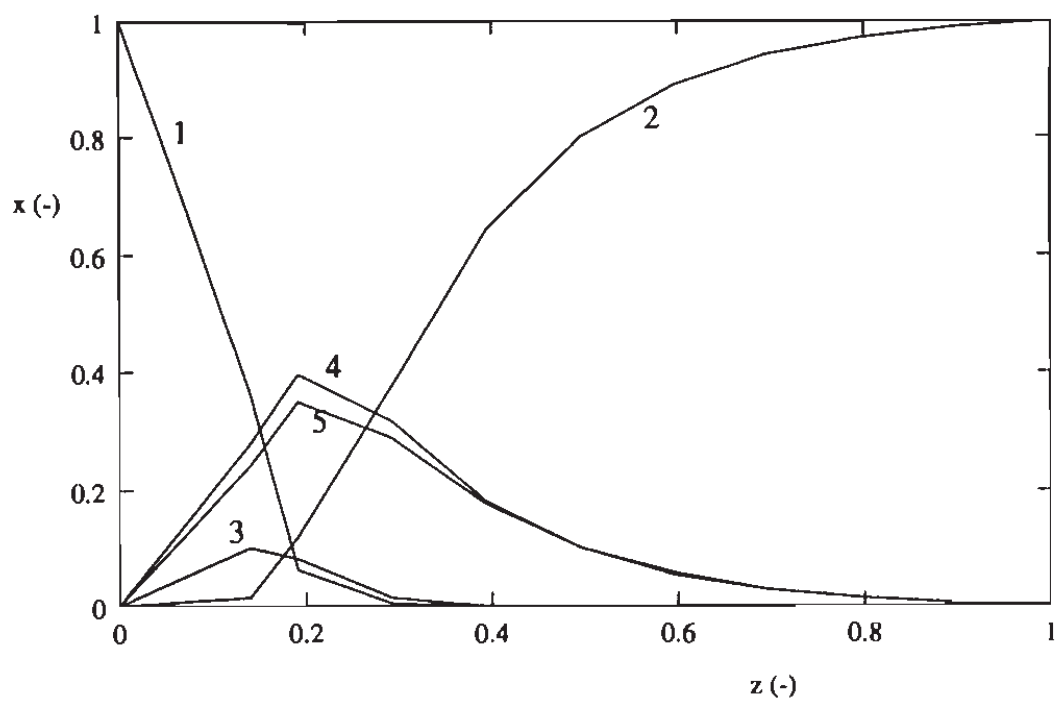

FIGURE 13 Typical profiles of reactants and products over the membrane for the reaction as given in Eq. (13). A transmembrane pressure difference $\Delta \Pi=1.0$ is present. Components: $1=A ; 2=\mathrm{O}_{2} ; 3=\mathrm{B} ; 4=\mathrm{CO}_{2} ; 5=\mathrm{H}_{2} \mathrm{O}$.

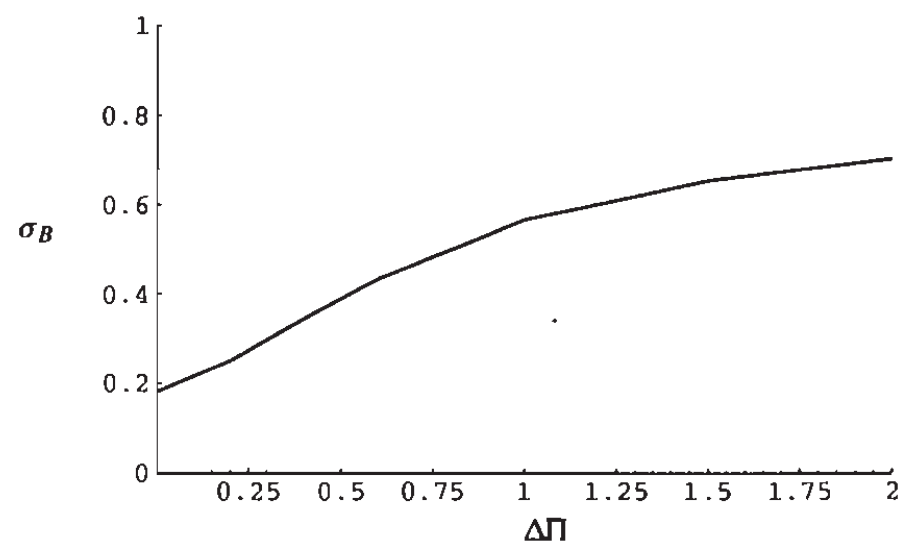

FIGURE 14 Selectivity towards B as a function of the transmembrane pressure difference for a consecutive reaction, see Eq. (13).

application of a transmembrane pressure difference increases the selectivity at increasing fluxes. This is a remarkable feature of the non-permselective membrane reactor which cannot be accomplished with conventional reactors. 


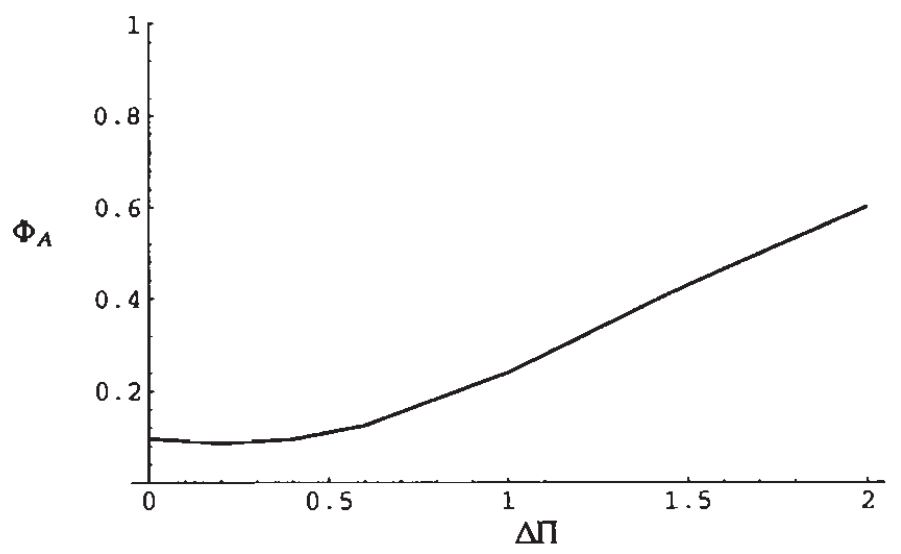

FIGURE 15 Total flux of $\mathrm{A}$ as a function of the transmembrane pressure difference for a consecutive reaction, see Eq. (13).

Perfect selectivity, however, cannot be obtained by application of a pressure difference. Enhanced transport of oxygen occurs, aided by the convective flux, but the fluxes of the component that should be transported upwind goes through a maximum, see Section 3.2. As a result slip of $\mathrm{O}_{2}$ occurs which will decrease the selectivity due to reaction at the external membrane surface. Furthermore, reactant slip will cause mixing of the reactants which might also be undesired from a safety viewpoint. However, Figures 14 and 15 clearly demonstrate that the non-permselective membrane reactor is attractive to improve intermediate product yields by application of a transmembrane pressure difference because it simultaneously enhances intermediate product yield and total conversion.

\section{CONCLUSIONS}

Model calculations were presented for various applications of a catalytically active membrane reactor for heterogeneously catalysed gas phase reactions. The model equations are based on the dusty gas model and from the model fluxes through the membrane, partial pressure profiles as well as overall conversions in a catalytic membrane reactor can be calculated for various process conditions. The model has been used to conduct a theoretical investigation of a catalytic membrane reactor with separated feed of reactants (CMRSR) for both irreversible and reversible reactions. 
Model calculations showed that high fluxes can be obtained in a nonpermselective CMR. The maximum attainable overall conversion in a CMRSR was not a function of the pore radius. Furthermore, a CMRSR offers a high flexibility and good controllability.

Application of a pressure difference over the membrane is a powerful control parameter in a CMRSR. Due to the presence of a transmembrane pressure difference the transport rates are increased substantially. Also the reaction products are preferentailly directed towards the low pressure side of the membrane, so that contamination of one of the feed streams with products can be avoided. The application of a pressure difference may significantly increase the selectivity when the CMR with separated feed of reactants is used for consecutive reactions. Due to its remarkable feature to enhance both fluxes and selectivity simultaneously, a non-permselective catalytic membrane with separated feed of reactants is an attractive novel reactor to operate multiple reactions.

\section{Acknowledgements}

This work was not possible without the financial support of GASTEC N. V., Apeldoorn, the Netherlands, which we gratefully acknowledge. Thanks also to $\mathrm{M}$. Bracht and R. Groenland for their contributions in the model calculations and development of the computer programs.

\section{NOTATION}

$B_{0} \quad$ permiability coefficient $\left(\mathrm{m}^{2}\right)$

$D_{i j} \quad$ binary diffusion coefficient of a mixture $i$ and $j\left(\mathrm{~m}^{2} \cdot \mathrm{s}^{-1}\right)$

$D_{i j}\left(\mathrm{P}_{0}\right) \quad D_{i j}$ evaluated at standard pressure $\mathrm{P}_{0}\left(\mathrm{~m}^{2} \cdot \mathrm{s}^{-1}\right)$

$D_{i, k} \quad$ Knudsen diffusion coefficient of component $i\left(\mathrm{~m}^{2} \cdot \mathrm{s}^{-1}\right)$

$E_{A} \quad$ enahncement factor, see Eq. (9) (-)

$f_{i} \quad$ ratio of reactor to catalyst volume, $V_{i} / V_{\text {cat }}$

$K_{0} \quad$ Knudsen coefficient (m)

$K_{c q} \quad$ equilibrium constant

$K_{\text {hyd }} \quad$ equilibrium constant of hydrogenation reaction

$K_{\text {dehyd }}$ equilibrium constant of dehydrogenation reaction

$k_{b} \quad$ backward rate constant of equilibrium reaction $\left(\mathrm{mol} \cdot \mathrm{m}^{-3} \cdot \mathrm{Pa}^{-2} \cdot \mathrm{s}^{-1}\right)$

$k_{f}$ forward rate constant of equilibrium reaction $\left(\mathrm{mol} \cdot \mathrm{m}^{-3} \cdot \mathrm{Pa}^{-2} \cdot \mathrm{s}^{-1}\right)$ 
$k_{h} \quad$ rate constant of hydrogenation reaction $\left(\left(\mathrm{mol} \cdot \mathrm{m}^{-3} \cdot \mathrm{Pa}^{-2} \cdot \mathrm{s}^{-1}\right)\right.$

$k_{d} \quad$ rate constant of dehydrogenation reaction $\left(\left(\mathrm{mol} \cdot \mathrm{m}^{-3} \cdot \mathrm{Pa}^{-2} \cdot \mathrm{s}^{-1}\right)\right.$

$k_{1,1} \quad$ reaction rate constant of reaction with $(1,1)$-order kinetics $\left(\mathrm{mol} \cdot \mathrm{m}^{-3} \cdot \mathrm{Pa}^{-2} \cdot \mathrm{s}^{-1}\right)$

$k_{r} \quad$ reaction rate constant for general kinetic powerlaw expression. Units depend on the exponents of the power rate law.

$L \quad$ membrane thickness (m)

$M \quad$ molecular mass $\left(\mathrm{kg} \cdot \mathrm{mol}^{-1}\right)$

$m \quad$ stoichiometric coefficient (-)

$n \quad$ total number of mole(cules)s

$n \quad$ stoichiometric coefficient

$N \quad$ flux, relative to a fixed co-ordinate system $\left(\mathrm{mol} \cdot \mathrm{m}^{-2} \cdot \mathrm{s}^{-1}\right)$

$P \quad$ total pressure $(\mathrm{Pa})$

$p_{i} \quad$ partial pressure of component $i(\mathrm{~Pa})$

$P e^{\prime} \quad$ Pe-number $L^{2} \phi_{\mathrm{v}} / V_{\text {cat }} D_{12}\left(P_{0}\right)$

$R_{g} \quad$ universal gas constant $\left(8.314 \mathrm{~J} \cdot \mathrm{mol}^{-1} \cdot \mathrm{K}^{-1}\right)$

$R_{i} \quad$ reaction rate with respect to component $i\left(\mathrm{~mol} \cdot \mathrm{m}^{-3}(\mathrm{cat}) \cdot \mathrm{s}^{-1}\right)$

$r_{p} \quad$ pore radius $(\mathrm{m})$

$T$ temperature (K)

$l \quad$ time (s)

$V \quad$ volume $\left(\mathrm{m}^{3}\right)$

$x \quad$ mole fraction $(-)$

$z \quad$ space coordinate of integration (m)

\section{Greek}

$\phi_{v} \quad$ volumetric flow rate $\left(\mathrm{m}^{3} \cdot \mathrm{s}^{-1}\right)$

$\varepsilon \quad$ porosity $\left(\mathrm{m}^{3}(\mathrm{gas}) \cdot \mathrm{m}^{-3}(\mathrm{cat})\right)$

$\mu \quad$ dynamic viscosity $(\mathrm{Pa} \cdot \mathrm{s})$

$\nu \quad$ stoichiometric coefficient

$\sigma \quad$ (differential) selectivity (-), see Eq. (16).

$\tau \quad$ tortuosity (-)

$\zeta \quad$ conversion (-)

see also Table I for the definition of dimensionless model parameters.

\section{Subscripts/superscripts}

$0 \quad$ gas phase or initial conditions

cat catalyst

$e \quad$ effective 
$\begin{array}{ll}i, j, A & \text { component } \\ K & \text { Knudsen } \\ 1 & \text { one ideally stirred cel in the setup of Figure } 2\end{array}$

\section{References}

[1] Saracco, G. and Specchia, V. (1994). Catal. Rev.-Sci. Eng., 36(2), 305.

[2] Hsieh, H. P. (1991). Cat. Rev.-Sci. Eng., 33(1\&2), 1.

[3] Shu, J., Grandjean, B. P. A., van Neste, A. and Kaliaguine, S. (1991). Can. J. of Chem. Eng., 69, 1036.

[4] Itoh, N. (1987). AIChE J., 33(9), 1576.

[5] Gryazov, V. M. (1992). Plat. Met. Rev., 36(2), 70.

[6] Sun, Y.-M. and Khang, S.-J. (1990). Ind. Eng. Chem. Res., 29, 232.

[7] Lund, C. R. F. (1992). Catal. Lett., 12, 395.

[8] Champagnie, A. M., Tsotsis, T. T., Minet, R. G. and Wagner, E. (1992). J. Catal., 134, 713.

[9] Mohan, K. and Govind, R. (1988). AlChE J., 34(9), 1493.

[10] Lund, C. R. F. (1992). Catal. Lett., 13, 423.

[11] Agarwalla, S. and Lund, C. R. F. (1990). J. Membrane Sci., 70, 129.

[12] Sloot, H. J., Versteeg, G. F. and van Swaaij, W. P. M. (1990). Chem. Eng. Sci., 45(8), 2415.

[13] Sloot, H. J., Smolders, C. A., van Swaaij, W. P. M. and Versteeg, G. F. (1992). AlChE J., 38(6), 887.

[14] Sloot, H. J., Versteeg, G. F., Smolders, C. A. and van Swaaij, W. P. M. (1991). 2nd. Int. Conf. Inorganic Membranes ICIM2-91, Montpellier, pp. 261-266.

[15] Zaspalis, V. T., van Praag, W., Keizer, K., van Ommen, J. G., Ross, J. R. H. and Burggraaf, A. J. (1991). Appl. Cat., 74, 249.

[16] Zaspalis, V. T., van Praag, W., Keizer, K., van Ommen, J. G., Ross, J. R. H. and Burggraaf, A. J. (1991). Appl. Cat., 74, 235.

[17] Veldsink, J. W., van Damme, R. M. J., Versteeg, G. F. and van Swaaij, W. P. M. (1992). Chem. Eng. Sci., 47, 2939.

[18] Veldsink, J. W., Versteeg, G. F. and van Swaaij, W. P. M. (1995). Ind. Eng. Chem. Res., 34, 763.

[19] Saracco, G., Veldsink, J. W., Versteeg, G. F. and van Swaaij, W. P. M. (1995). Chem. Eng. Sci., 50, 2005.

[20] Saracco, G., Veldsink, J. W., Versteeg, G. F. and van Swaaij, W. P. M. (1995). Chem. Eng. Sci., 50, 2833.

[21] Mason, E. A. and Malinauskas, A. P. (1983). Gas transport in porous media: The dusty gas model (Elsevier, Amsterdam, The Netherlands).

[22] Veldsink, J. W., van Damme, R. M. J., Versteeg, G. F. and van Swaaij, W. P. M. (1995). Chem. Eng. J., 57, 115.

[23] Itaya, Y., Miyoshi, K., Maeda, S. and Hasatani, M. (1992). Int. Chem. Engng., 32(1), 123.

[24] Veldsink, J. W., Versteeg, G. F. and van Swaaij, W. P. M. (1995). Chem. Eng. J., 57, 273.

[25] Trimm, D. L. and Lam, C. W. (1980). Chem. Eng. Sci., 35, 1405.

[26] Wcstcrterp, K. R., van Swaaij, W. P. M. and Beenackers, A. A. C. M. (1984). Chemical reactor design and operation (Wiley and Sons, New York), 2nd edn., Ch. 7.

[27] Novak, M., Ehrhardt, K., Klusacek, K. and Schneider, P. (1988). Chem. Eng. Sci., 43(2), 185.

[28] Harold, M. P., Zaspalis, V. T., Keizer, K. and Burggraaf, A. J. (1993). Chem. Eng. Sci, 48(15), 2705. 